\title{
Effects of Carbon Source, Carbon Concentration and Culture Conditions on in vitro Rooting of Pinus pinea L. Microshoots
}

\author{
A. Zavattieri1, M. Lima11, V. Sobral1, P. Oliveira2 and A. Costa 3 \\ (1) Laboratório de Melhoramento e Biotecnologia Vegetal, Instituto de Ciências Agrárias \\ Mediterrânicas (ICAM), Universidade de Évora Portugal. (2) Laboratório de \\ Microbiologia do Solo (ICAM), Universidade de Évora, Portugal (3) Laboratório de \\ Fisiologia Vegetal (ICAM), Universidade de Évora, Portugal
}

Keywords: Stone pine, rhizogenesis, glucose, sucrose, temperature, light, acclimation

\begin{abstract}
Clonal propagation via adventitious bud stimulation from cotyledon explants has been reported before in stone pine (Pinus pinea L.), however the number of rooted shoots had low frequency and short growth span. Therefore the main objective of the present work was to increase the number and quality of roots per shoot in order to ensure the survival and growth of a great number of plants in the acclimation phase. To achieve this, different combinations of carbon source (sucrose or glucose) at different concentrations, under different environmental conditions (temperature and light), were tested in the induction and expression phases of the adventitious root formation. Shoots of different clones obtained via organogenesis have been employed for the experiments. Observations were made on the rooting percentage, root length and number of roots per shoot. The results showed a general increased of the number of roots per shoot and an earlier root formation when glucose was used as a carbon source. However, there were no differences in the percentage of rooting between the carbons sources tested. The best results were obtained using $0.117 \mathrm{M}$ of glucose and dark treatment combined with $19^{\circ} \mathrm{C}$ during the induction phase of the rhizogenic process. Light and low sugar concentration proved to be beneficial for the expression phase, increasing the root length. A remarkable interclonal difference in the ability to form roots was observed. It was possible to obtain a rooting percentage of more than $75 \%$ in several of the tested clones.
\end{abstract}

\section{INTRODUCTION}

Stone pine is increasingly sought due to the high demand for pine nut. While providing an economically viable supply for such demand, overcoming current difficulties in the process of micropropagation of this species may also open the way to handling other intractable pine species and other conifers. In particular, the design of novel formulations may also provide clues to the fundamental biology of adventitious root formation, a poorly understood subject, in spite of its determining role in the future success of applying micropropagation to a broader range of Mediterranean woody plants.

Although clonal propagation of stone pine via adventitious bud stimulation from cotyledon explants was reported (Capuana, 1994; Oliveira, 2003), rooting of shoots remains the bottleneck of the micropropagation process, reducing the possibilities of applying this technique on a large scale. 
Root induction is a complex morphogenic process that involves a major metabolic switch. Although auxins are the main factors involved in the induction of rooting, other endogenous and exogenous substances also influence the rhizogenic process. Moncousin (1991) discussed factors like the basal medium concentration, the carbohydrate nutrition, light, darkness, temperature and the presence of phenolic compounds. However, the rhizogenic process is not limited to root induction, since other two steps, expression and root elongation are recognised (Damiano, 1991). Factors that influence each of these steps are not necessarily the same.

The goals of the study were to achieve a high rate of rooted plants for a large scale propagation of stone pine clones, with regard to the effect of different carbon sources and their concentrations, different light regimes and temperatures. A set of conditions that allow for such goals, at least in some clones, are reported.

\section{MATERIAL AND METHODS \\ Plant material}

Mature seeds of stone pine were obtained on February 2003 from selected trees (for seed production) in the Region of Alcácer do Sal, Alentejo, Portugal and stored in a cold chamber at $4{ }^{\circ} \mathrm{C}$ until used.

\section{Shoot induction and multiplication}

Stone pine seeds shells were removed and the integuments surface-disinfected, the intact cotyledons of each seed (12 to 14) were placed in a single Petri dish with solid Woody Plant Medium (WPM; Lloyd and Mc Cown, 1980) supplemented with N6 Benzylaminopurine (BAP) at $22.1 \mu \mathrm{mol}(5 \mathrm{mg} / \mathrm{L})$, sucrose $(2 \%)$ and Difco Bacto-Agar $(0.7 \%)$. The $\mathrm{pH}$ was adjusted to 5.8 using $\mathrm{NaOH}(1 \mathrm{~N})$ before autoclaving. The culture chamber conditions during the shoot induction phase were $25 / 19{ }^{\circ} \mathrm{C}$ (day/night temperatures) with $16 \mathrm{~h}$ photoperiod by cool-white fluorescent light at $80 \mu \mathrm{mol} \mathrm{s} \mathrm{m}^{-2}$. As soon as the micro-shoots were easy to individualise from these cotyledons, they were transferred for shoot elongation to test tubes (one per tube) with $10 \mathrm{ml}$ of the same basal medium supplemented with sucrose $(2 \%)$ and activated charcoal $(0.2 \%)$ in the absence of added growth regulators. All cuttings collected from a single seed were identified with the same clonal number.

The multiplication medium consisted of solid WPM, with $100 \mathrm{mg} / \mathrm{L}$ of myoinositol, sucrose (2\%) and gelled with agar-agar (Merck) $0.65 \%$ and $0.2 \%$ activated carbon. When the micro-shoots reached at least $2 \mathrm{~cm}$ length they were transferred to rooting medium.

\section{Rooting conditions}

Different combinations of carbon source, light and temperature were tested for the induction and expression phases of the rhizogenic process. The basal medium used for all rooting experiments was WPM containing Difco Bacto-Agar $(0.65 \%)$ and a carbon source (see below), and adjusted to $\mathrm{pH} 5.8$ using $\mathrm{NaOH}(1 \mathrm{~N})$ before autoclaving. For the induction phase (two weeks) this medium was supplemented with NAA (Naphthalene acetic acid) $10.7 \mu \mathrm{M}(2 \mathrm{mg} / \mathrm{L})$ as in Oliveira (2003), followed by the expression phase on WPM basal medium without growth regulators and $0.0584 \mathrm{M}(20 \mathrm{~g} / \mathrm{L})$ of sucrose, $16 \mathrm{~h}$ photoperiod, $25 / 19{ }^{\circ} \mathrm{C}$ day/night temperatures. The expression phase conditions and medium were the same for all the experiments. 
For all the experiments rooting percentage, number of shoots with roots, number of roots per shoot and length of the main root were evaluated at 30 and 45 days after the induction phase. The results presented here are the mean of 24 explants per clone. All experiments were carried out with three repetitions and the results were compared through analysis of variance (ANOVA) and Duncan's Multiple Range Test.

\section{Experiment 1: rooting with different sucrose concentration in the induction and expression phases}

In order to determine if sucrose concentration in the WPM medium could influence the rooting process, two different combinations of sucrose were used: (a) 0.117 $\mathrm{M}(40 \mathrm{~g} / \mathrm{L})$ in the induction phase and $0.0584 \mathrm{M}(20 \mathrm{~g} / \mathrm{L})$ in the expression phase and (b) $0.0584 \mathrm{M}(20 \mathrm{~g} / \mathrm{L})$ in the induction phase and $0.117 \mathrm{M}(40 \mathrm{~g} / \mathrm{L})$ in the expression phase. Only the induction medium was supplemented with NAA $10.7 \mu \mathrm{M}(2 \mathrm{mg} \mathrm{L}-1)$. The shoots were incubated for one week in the dark at $19{ }^{\circ} \mathrm{C}$, and for one additional under $16 \mathrm{~h}$ photoperiod with the same temperature.

\section{Experiment 2: rooting with different carbon sources}

In order to determine the influence of the carbon source on the induction phase of the rooting process modified WPM containing either $0.117 \mathrm{M}(40 \mathrm{~g} / \mathrm{L})$ of sucrose or $0.117 \mathrm{M}(23,185 \mathrm{~g} / \mathrm{L})$ of glucose was used. All other conditions were exactly the same as in the experiment described above. The expression conditions were the same as describe in rooting conditions.

\section{Experiment 3: rooting with different carbon source and temperatures in the first two weeks (induction phase)}

The effect of the two different temperatures $\left(19{ }^{\circ} \mathrm{C}\right.$ and $\left.25^{\circ} \mathrm{C}\right)$ during the first two weeks (root induction phase) was tested in combination with the carbon sources and concentrations used in the Experiment 2.

\section{Pre acclimation phase}

To prepare the plantlets for the acclimation phase and to ensure the activation of the photosynthetic system, they were placed in WPM medium with $0.029 \mathrm{M}(10 \mathrm{~g} / \mathrm{L})$ sucrose and $0.2 \%$ activated charcoal for one week. The culture conditions were $16 \mathrm{~h}$ photoperiod, $25 / 19^{\circ} \mathrm{C}$ day/night temperatures.

\section{Acclimation}

Rooted plantlets were transferred to $250 \mathrm{ml}$ bottles containing $15 \mathrm{~g}$ of sterile vermiculite soaked with $1 / 4$ strength WPM, without sucrose. Aluminium foil was wrapped around the bottles to cover the substrate laterally, thus protecting roots from light. This protection was weekly removed, to observe root elongation and root hair development, and placed back (no measurements were made). The top of the bottles was covered with perforated plastic film in order to adapt the plantlets gradually to the external humidity conditions. The plants grew in a growth chamber at $25 / 19{ }^{\circ} \mathrm{C}$ day/night temperatures and $80 \%$ relative humidity, with $16 \mathrm{~h}$ photoperiod $\left(270 \mu \mathrm{mol} \mathrm{s} \mathrm{s}^{-1}\right)$ for 10 weeks. The relative humidity of the growth chamber was gradually decreased to $60 \%$. Plants were watered as required with alternating sterile water and the same diluted WPM without sucrose. 
Plants were then transferred to pots containing vermiculite-peat-sand (1:1:1 by weight) as a growing substrate and maintained under the same growth conditions with regular watering.

\section{RESULTS AND DISCUSSION \\ Experiment 1: different sucrose concentrations in the induction and expression phases}

The rooting percentage and the number of roots per shoot were significantly $(\mathrm{p} \leq$ 0.05) higher when higher sucrose concentration was used in the induction phase of the rhizogenic process followed by a decreased sucrose level during the expression phase (Fig.1). All clones placed in the induction medium containing high concentration of sucrose $(0.117 \mathrm{M})$ formed roots when transferred to the expression medium; on the contrary clones 103 and 33 did not form roots in the expression medium when the induction medium had the lowest sucrose content $(0.0584 \mathrm{M})$.

These observations are in agreement with the beneficial effects of increased sucrose concentration during pre-rooting and rooting in Quercus robur (Simpson and Marcks, 1995) and Vitis (Gribaudo and Restagno, 1995). Rooting of micro-cuttings demands a continuous availability in free sugars (Gaspar and Coumand, 1987). Even though an important enrichment in sucrose may improve the rooting of certain plants, high additions of sucrose have negative effects, which can be explained for the interaction between carbohydrates and light. High concentration of sucrose during the expression phase in light have negative effects which can be explained by the accumulation of inhibitors or by the reduction of promoters (Ellianson and Brunes, cited by Moncousin, 1991), by the transformation of added sugars in soluble and storage forms (Haissig, 1984b cited by Moncusin, 1991) but also by the fact that ratios between nitrogen and sucrose, or auxin and sucrose (Hyndeman et al., 1982; Welander, 1976 cited by Moncusin, 1991).

\section{Experiment 2: glucose vs. sucrose}

The exogenous application of sucrose (in the presence or absence of auxin) is known to be beneficial for the rooting of a large number of herbaceous and woody plants (Haissig, 1982). Sucrose is the most common choice in tissue culture media, because it is the main sugar translocated in the phloem of many plants. However, other carbohydrates such as glucose, fructose and mixtures of monosaccharides have been used to improve embryogenic or organogenic processes (Last and Bretell, 1990).

In this work the rooting percentage was not significantly different $(p \leq 0.05)$ between carbon sources tested in the induction phase; nevertheless, the percentage or rooted shoots in glucose was higher than that of sucrose for all the tested clones. Differences in rhizogenic aptitude were evident among clones (apparently without interaction with the carbon source used).

The main difference between the carbon sources was in the number of roots per shoot, being significantly $(\mathrm{p} \leq 0.05)$ higher in glucose (Fig. 2). Shoots in sucrose formed one well-defined root with a small callus at the base of the shoot. Glucose induced the formation of multiple adventitious roots per shoot (three was the modal number) (Fig. 3). This represents an advantage for the early stages of the acclimation. Another observation was that glucose reduced the time for roots to appear, but the root length was greater in sucrose (data not shown). These results are similar with those reported by Romano (1994) for Quercus suber. 


\section{Experiment 3: different carbon source and temperature}

The positive effect of low temperature and darkness used in the induction phase (first two weeks) is demonstrated by the differences in the rooting percentage obtained at $19^{\circ} \mathrm{C}$ compared with $25^{\circ} \mathrm{C}$. The rooting percentage for the 8 clones tested was significantly $(\mathrm{p} \leq 0.05)$ higher when the first two weeks the shoots were at $19{ }^{\circ} \mathrm{C}$ independently of the carbon source used: glucose or sucrose (Fig. 4). A great variability could be observed between clones especially when the temperature was $25^{\circ} \mathrm{C}$. The number of roots per shoot was also significantly higher when the induction phase occured at $19{ }^{\circ} \mathrm{C}$ independently of the carbon source used (Fig. 5).

These results are in agreement with those reported on Pseudotsuga menziesii (Cheng and Vouqui, 1977), Pinus radiata (Smith, 1986) and cuttings from various woody plants (Hansen and Potter, 1997). In Picea glauca, rooting was greater with a 20/18 ${ }^{\circ} \mathrm{C}$ temperature regimes compared with $24 / 18^{\circ} \mathrm{C} ; 20 / 15^{\circ} \mathrm{C}$ or $25 / 25^{\circ} \mathrm{C}$ (Rumary and Thorpe 1984 cited by Ellis and Webb, 1993), and in Douglas fir $19^{\circ} \mathrm{C}$ gave increased rooting and normal plants, while at $24^{\circ} \mathrm{C}$ few roots formed and the root junction callus formed causing discontinuity in the vascular system (Cheng, 1978 cited by Ellis and Webb 1993).

Other possible explanation of these observations could be finding in Mohammed and Vidaver (1988), they speculate that light and temperature affect rooting by controlling auxin and so dark and low temperature would have a promoting effect as happened in this work. Also, less cell wall deposition, less vascular tissue and thinner walls are expected in dark conditions, that could facilitate the movements of exogenous plant growth regulator to explant regeneration sites (Hartmann et al., 1997). It could be explained also, that darkness in the induction phase would promote a higher proportion of undifferentiated cells (Hutchinson et al., 1999) so undifferentiated cells may improved root organogenesis, as probably happened in this work. Other possible effect of low temperature and darkness could be explained by their influence on auxin metabolism in relation to root formation, especially by modifying peroxidase and endogenous phenolic compounds activities (Druart et al., 1982).

\section{Acclimation}

While in the vermiculite, both the shoots and root system of all plants developed noticeably in particular, they displayed fairy-elongated roots with dense root hairs. The simple method of increasing weekly the number of perforations in the plastic film that covered the bottles, was very efficient to adapt the plantlets to the external humidity conditions. For this reason, plant survival during acclimation on pots was $90 \%$, but the development was slow.

\section{CONCLUSIONS}

The present results increased the possibilities of obtaining a reliable protocol for rooting stone pine shoots. A percentage of $75 \%$ in the rooting process for stone pine had never been reached before. Our results also exemplify that the rhizogenic process is a multiple step process and care must be taken in the media and conditions of each of the phases.

A combination between high glucose content $(0.117 \mathrm{M})$ and $19{ }^{\circ} \mathrm{C}$ in the presence of $10,7 \mu \mathrm{M}$ NAA for the induction medium follow by an expression medium with sucrose at $0.0587 \mathrm{M}$, without growth regulators and in $25 / 19^{\circ} \mathrm{C}$ day/night temperatures were the best combinations for rooting stone pine microshoots. 
More studies are required in the acclimation phase to compare the development of the rooting systems and the aerial plants parts of the different treatment in the rooting process.

\section{Literature cited}

Capuana, M. 1994. Le culture in vitro nel genere Pinus. Monti e Boschi. No 5:24-30

Cheng, T. and Vouqui, T. 1977. Regeneration of Douglas-fir plantlets through tissue culture. Science. 198:306-307

Damiano, C., Chiariotti, A. Caboni, E., Quarta, R. and Boumis, G. 1991. Some factors affecting the induction and expression of rooting in different fruit species in vitro. Acta Hort. 300:211-224

Druart, P., Kervers, C., Boxus, P. and Gaspar, T. 1982. In vitro promotion of root formation by apple shoots through darkness effect on endogenous phenols and peroxidases. Z. Pflanzenphysiol. 108:429-436

Ellis, D.D. and Webb, D.T. 1993. Ligth regimes used in conifer tissue culture. In: Ahuja M.R. (eds.). Micropropagation of woody culture plants. (pp.31-55). Kluwer Academic Publishers. Netherlands

Gaspar, T. and Coumans, M. 1987. In Bonga JM, Durzan DJ (eds.). Cell and Tissue Culture in Forestry. Martinus Nijhoff Publisher. Dordrecht (pp202-217)

Gribaudo, I. and Restagno, M. 1995. Influence of sucrose concentration on axillary bud proliferation in micropropagated grapevine. Bull. Rech. Agron. Gembloux. 30(1-2): 59-65

Haissig, B.E. 1982. Carbohydrate and amino acid concentration during adventitious root primordium development in Pinus banksiana Lamb., cuttings. For. Sci. 61:13-19

Hansen, O.B. and Potter, J.R. 1997. Rooting of apple, rhododendron and mountain laurel cuttings from stock plants etiolated under two temperatures. HortSc. 32(2):304-306

Hartmann, H.T., Kester, D.E., Davis, Jr. F.T. and Geneve, R.L. 1997. Plant propagation: Principles and Practices, 6th ed. Prentice Hall, Inc. Englewood Cliffs, NJ

Hutchingson, K.W., Singer, P.B., Mc Innis, S., Dias-Sala, C. and Greenwood, M.S. 1999. Expansins are conserved in conifers and expressed in hypocotyls in response to exogenous auxin. Plant Physiol. 120:827-831

Last, D.I. and Brettell, R.I.S. 1990. Embryo yield in wheat anther culture is influence by the choice of sugar in the culture medium. Plant Cell Rep. 9:14-16

Lloyd, G.B., and Mc. Cown, B.H. 1980. Commercially-feasible micropropagation at mountain-laurel (Kalmia latifolia), by the use of shoot tip culture. Int. Plant Prop. Proc. 30:421-427

Mohammed, G. and Vidaver, W. 1988. Root production and plantlet development in tissue culture conifers. Plant Cell Tiss. Org. Cult. 14:137-160

Moncousin, C. 1991. Rooting of microcuttings: general aspects. Acta Hort. 289:301-310

Oliveira, P., Barriga, J., Cavaleiro, C., Peixe, A., Potes, A. 2003. Sustained in vitro root development obtained in Pinus pinea L. inoculated with ectomycorrhizal fungi. Forestry 76(5): 579-587

Romano, A., Noronha, C. and Martins-Loução, M.A. 1995. Role of carbohydrates in micropropagation of cork oak. Plant Cell Tiss. Org. Cult. 40:159-167

Smith, D.R. 1986. Radiata pine (Pinus radiata D. Don). Biotechnology in Agriculture and Forestry. Vol. I. Trees I . pp.274-291. Springer-Verlag. Berlin 
Simpson, S.E. and Marks, T.R. 1995. The role of sucrose in shoot development leading to rhizogenesis in vitro in juvenile and mature pedunculate oak (Quercus robur). Bull. Rech. Agron. Gembloux. 30(1-2):77-86

\section{Figures}

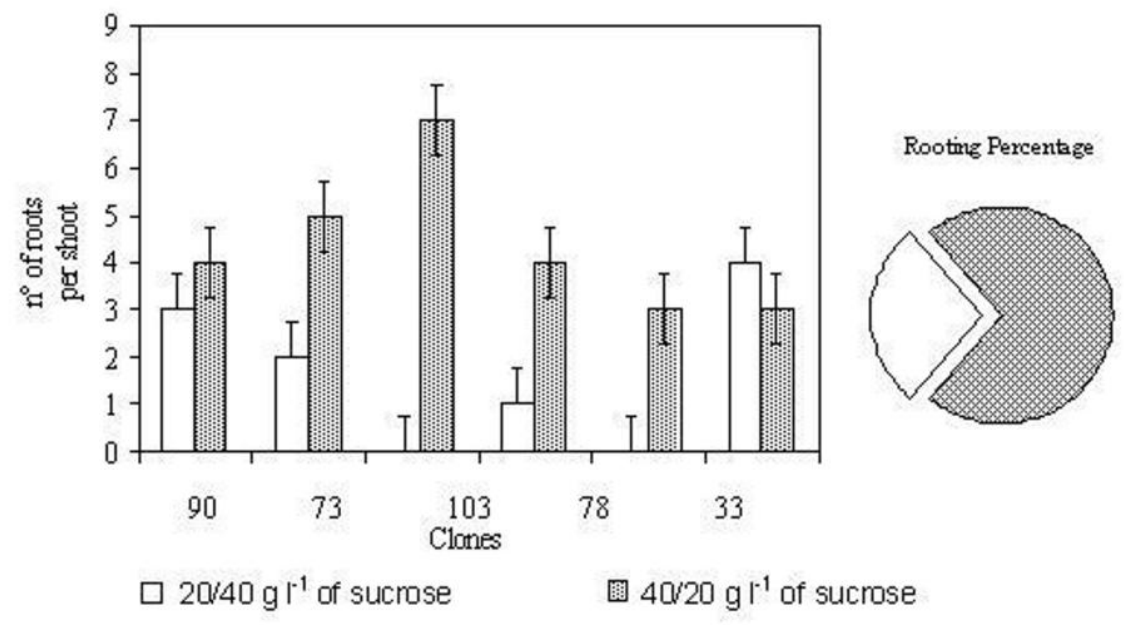

Fig.1. Effect of sucrose concentration in the induction and expression phases on the number of roots formed per clone $(p<0.05)$ and in the total percentage of rooted plantlets for the tested concentrations

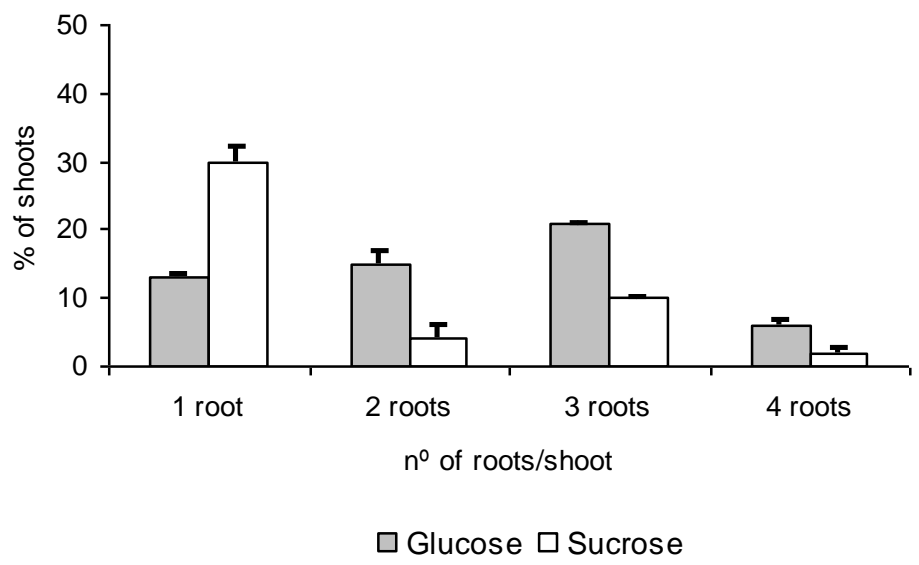

Fig. 2. Percentage of shoots that formed 1, 2, 3 or 4 roots on sucrose or glucose supplemented media 

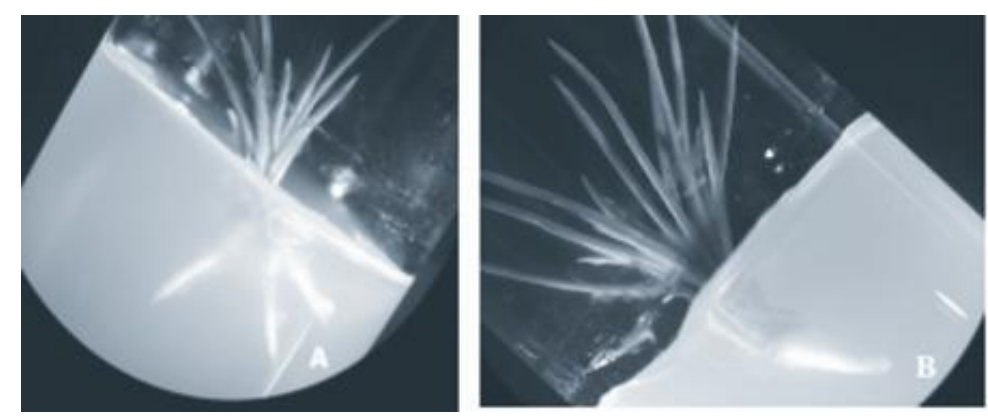

Fig. 3. Glucose induced the formation of various roots per shoot (A), while sucrose formed preferentially one well defined root

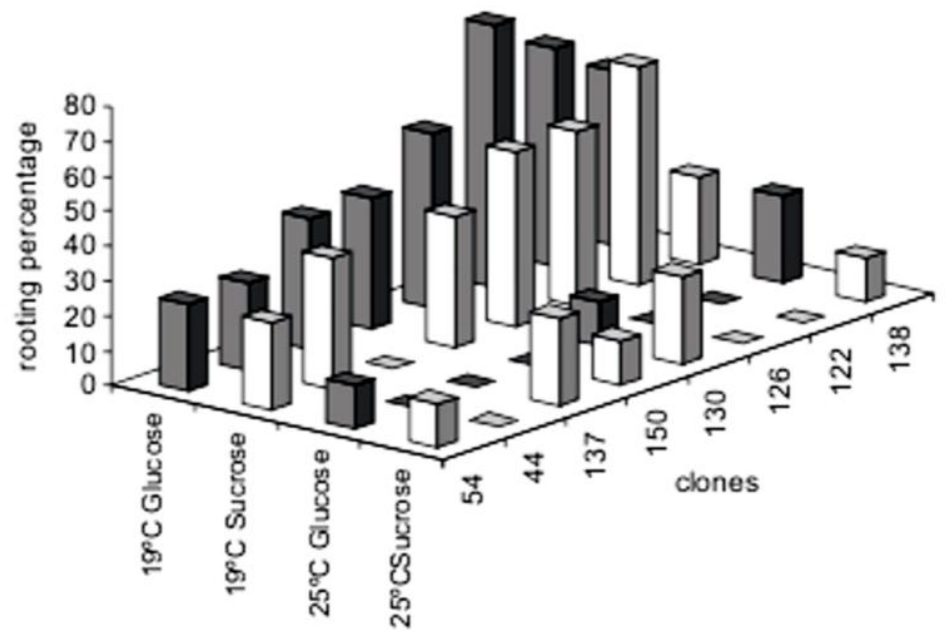

Fig. 4. Effect of carbon sources and temperatures in the induction phase of the rhizogenic process on the rooting percentage of the clones tested.

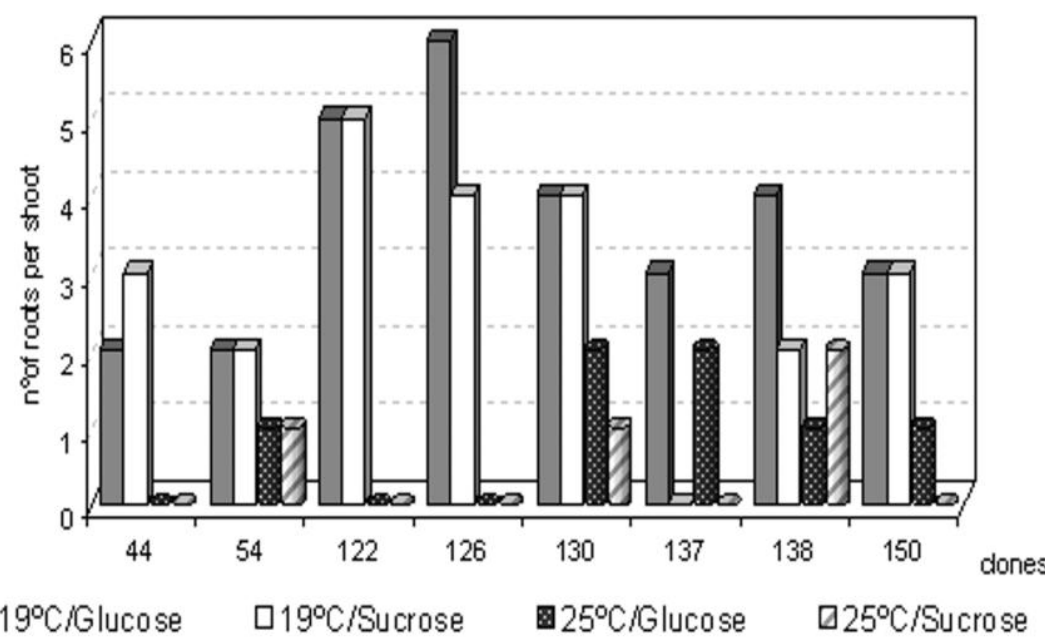

Fig. 5. Influence of carbon sources and temperature on the number of adventitious roots formed per shoot for all the clones tested. 